\title{
Cardiac Risk in Prediction Models
}

\author{
Hisashi Adachi
}

Department of Community Medicine, Kurume University School of Medicine, Kurume, Japan

\section{See article vol. 28: 816-825}

There are several exceptional models for cardiac risk prediction in the U.S. and Japan. In the U.S., the Framingham coronary heart disease (CHD) prediction scores were used to assist clinicians in estimating the absolute risk of any individuals ${ }^{1)}$. Recently, some studies have reported a 10-year cardiac risk using Framingham risk score (FRS) ${ }^{2-4}$. Lagerweij GR, et al. ${ }^{4)}$ suggested that the absolute predicted 10 -year risks from different prediction models cannot be directly compared, and that treatment decisions often depend on which prediction model is applied and its recommended risk threshold, introducing unwanted practice variation into risk-based preventive strategies for cardiovascular disease (CVD). In our country, the Suita score was also developed to predict CHD for the Japanese urban population ${ }^{5)}$. Using the score, prediction of CHD model for patients with cardiac diseases was made in the Japan Atherosclerosis Society Guidelines for Prevention of Atherosclerotic Cardiovascular Diseases $2017^{6}$. Moreover, a new risk prediction model of CHD in participants with and without diabetes was also assessed ${ }^{77}$. In particular, Nishimura K, et al. ${ }^{5)}$ reported that a predictive score as a coronary risk factor for the Japanese population was more accurate for predicting CHD than the original FRS. Hirai $\mathrm{H}$, et al. ${ }^{7)}$ also showed that their new models could be useful to predict 3-year risk of CHD at least in the Japanese population and particularly in diabetic subjects.

Menotti A, et al. ${ }^{8)}$ reported that the magnitude of multivariable coefficients and hazard ratios of four cardiovascular risk factors across five worldwide regions of the Seven Countries Study (SCS) in predicting 50-year coronary deaths were compared. In the Tanushimaru study, one of the cohorts of the SCS, we have presented a computer model to predict individual survival and death based on six conventional atherosclerotic risk factors for the first time, using the supervised statistical pattern recognition method ${ }^{9)}$. Unfortunately, this model was not used to predict $\mathrm{CHD}$ risk because of the extremely low incidence of CHD in our cohort.

Recently, Li Y, et al. ${ }^{10)}$ reported the absolute 10 -year risk of death from CHD, stroke, and CVD in 44,869 individuals in the age group of 40-79 years from 8 Japanese prospective cohorts. The strength of their study is the integrated individual participant data from multiple high-quality prospective cohorts with relatively recent baseline year along with the fact and that the large sample size enables creation of prediction models by CHD, stroke, and CVD. Moreover, these models showed good response in case of both men and women in terms of discrimination across end points for not only CHD but also stroke or CVD. This study appears to be very novel compared with the other studies mentioned above.

\section{Conflicts of Interest}

None.

\section{References}

1) D’Agostino RB Sr, Grundy S, Sullivan LM, Wilson P; CHD Risk Prediction Group. Validation of the Framingham coronary heart disease prediction scores: results of a multiple ethnic groups investigation. JAMA, 2001; 286: 180-187

2) Al-Shamsi S. Performance of the Framingham coronary heart disease risk score for predicting 10-year cardiac risk in adult United Arab Emirates nationals without diabetes: a retrospective cohort study. BMC Fam Pract, 2020; 21: 175

3) Lagerweij GR, Moons KGM, de Wit GA, Koffijberg H. Interpretation of CVD risk predictions in clinical practice: Mission impossible? PLoS One, 2019; 14: e0209314

4) Zhou J, Gao Q, Wang J, Zhang M, Ma J, Wang C, Chen H, Peng X, Hao L. Comparison of coronary heart disease risk assessments among individuals with metabolic 
syndrome using three diagnostic definitions: a crosssectional study from China. BMJ Open, 2018; 8: e022974

5) Nishimura K, Okamura T, Watanabe M, Nakai M, Takegami M, Higashiyama A, Kokubo Y, Okayama A, Miyamoto Y. Predicting coronary heart disease using risk factor categories for a Japanese urban population, and comparison with the framingham risk score: the Suita study. J Atheroscler Thromb, 2014; 21: 784-798

6) Kinoshita M, Yokote $K$, Arai $H$, Iida M, Ishigaki $Y$, Ishibashi S, Umemoto S, Egusa G, Ohmura H, Okamura T, Kihara S, Koba S, Saito I, Shoji T, Daida H, Tsukamoto K, Deguchi J, Dohi S, Dobashi K, Hamaguchi H, Hara M, Hiro T, Biro S, Fujioka Y, Maruyama C, Miyamoto Y, Murakami Y, Yokode M, Yoshida H, Rakugi H, Wakatsuki A, Yamashita S; Committee for Epidemiology and Clinical Management of Atherosclerosis. Japan Atherosclerosis Society (JAS) Guidelines for Prevention of Atherosclerotic Cardiovascular Diseases 2017. J Atheroscler Thromb, 2018; 25: 846-984

7) Hirai H, Asahi K, Yamaguchi S, Mori H, Satoh H, Iseki K, Moriyama T, Yamagata K, Tsuruya K, Fujimoto S, Narita I, Konta T, Kondo M, Shibagaki Y, Kasahara M,
Watanabe T, Shimabukuro M. New risk prediction model of coronary heart disease in participants with and without diabetes: Assessments of the Framingham risk and Suita scores in 3-year longitudinal database in a Japanese population. Sci Rep, 2019; 9: 2813

8) Menotti A, Puddu PE, Adachi H, Kafatos A, Tolonen H, Kromhout D. The strength of the multivariable associations of major risk factors predicting coronary heart disease mortality is homogeneous across different areas of the Seven Countries Study during 50-year follow-up. Acta Cardiol, 2018; 73: 148-154

9) Ogata K, Miyamoto T, Adachi H, Hirai Y, Enomoto M, Fukami A, Yokoi K, Kasahara A, Tsukagawa E, Yoshimura A, Obuchi A, Nakamura S, Imaizumi T. New computer model for prediction of individual 10-year mortality on the basis of conventional atherosclerotic risk factors. Atherosclerosis, 2013; 227: 159-164

10) Li Y, Yatsuya H, Tanaka S, Iso H, Okayama A, Tsuji I, Sakata K, Miyamoto Y, Ueshima H, Miura K, Murakami Y, Okamura T, EPOCH-JAPAN Research Group. Estimation of 10-year risk of death from coronary heart disease, stroke, and cardiovascular disease in a pooled analysis of Japanese cohorts: EPOCH-JAPAN. J Atheroscler Thromb, 2021; 28: 816-825 